\title{
Schooling Degree, Social Position and Occupational Destinations: University Graduates
}

\author{
Odaci Luiz Coradini \\ Professor of social sciences \\ Federal University of Rio Grande do Sul (UFRGS) \\ Porto Alegre, Brazil.
}

\begin{abstract}
The central theme of this paper is the relationships between the occupational destination of university graduates and their incomes. This occupational destination includes the occupation and the status in employment. The general hypothesis is that, more than the area of training and occupational categories, the most important factor for a higher position in the income hierarchy is the association with management or command occupations. This occurs both in terms of occupation, with the group for legislators, senior officials and managers systematically at the top, and in terms of status in employment, with employers or equivalent always in the highest position. Thus, in addition to the differences in income between the occupational categories, when correlating them with their status in employment, a second hierarchy emerges in conformity with the relationships with their categories. Seven countries were analysed and the results were systematically recurrent, with only minor variations.
\end{abstract}

Keywords: occupational destination and appreciation of education; schooling degree and social position; occupational destination and income; command position and income; position in the occupation and income.

\section{Introduction}

The central theme of this paper is the relationships between the occupational destinations of university graduates and their incomes. It is assumed that, despite the empirical specificity of the theme, it covers a series of more general problems of sociological analysis. Although not all of these problems can be exhausted, particularly due to the limits of the available sources of empirical material, it seems possible to advance the exploration and the explanation of evidence for some of these problems. Among these themes, the one regarding the relationships between the appreciation of formal education and social position is the most prominent.

When empirically addressing the relationships between the occupational destination of university graduates and their social positions, one of the central analytical axes consists of the conditions of appreciation of academic degrees or of schooling in general. In general and explicit terms, here the discussion turns towards the confrontation between theoretical positions, which presuppose the value of education as something intrinsic that economically would be the result of the supposed increase of productivity at work, and, at the opposite pole, those positions based on assumptions of dependence of the social conditions on the uses of an academic degree. Regarding the first position, the perspective associated with the human capital theory is highlighted, and, in the second, in addition to the positions associated with credentialism, Bourdieu's perspective is particularly emphasised.

However, as top social positions are systematically occupied by managers and so on, it is worth mentioning another general problem which is the origin of the premises of some of these positions, particularly in relation to credentialism and to Bourdieu's approach. This problem deals with the formulations of Weber, especially the relationships between what is objectified and explicitly encoded in the social structure and the implicit or indirect principles and means of action and legitimation. In all of Weber's (1984: 682-694) works, this differentiation occurs especially or more directly and explicitly in the opposition, between the concept of class and status group or estate. In view of the subsequent appropriations, the conditions of social objectivities must be highlighted; as an exemplary case of that, we have bureaucracy or rational/legal domination in general. An aspect that must be highlighted is that in its relationships with instrumental rationality or rational/legal domination, the administrative body is not subordinate and thus not governed by bureaucratic rules (Weber, 1984: 708-716). The occupational group, situated at the top of the hierarchy of incomes and appreciation of academic degree, consists of legislators, senior officials and managers and, in relation to the status in employment, of employers. Therefore, it is about specific positions, with respect to the rules of bureaucracy, and the social division of labour.

Together with the multidimensionality of social structure, this assumption of relationships between what is socially objectified and encoded as such and the implicit or indirect resources and principles of legitimation is, in some way, at the foundation of all theoretical positions that contradict the theory of human capital. 
However, neither does this eliminate internal controversies and private perspectives, which may have different reasons, nor Weber's own ambivalences regarding relationships between academic degree or technical expertise and social structure, as highlighted by Bourdieu (1989: 537-538). However, these controversies can also be due to specific appropriations, centred on a specific perspective, as is the case of the formulations that came to be defined as credentialism. In that case, the relationships between the socially objectified dimensions and the principles and dynamics of social hierarchisation are viewed especially from the perspective of their 'credential' effects in the appreciation of the academic degree. Similarly, in Bourdieu's case these relationships between what is socially objectified and the implicit principles of social hierarchisation are formulated as such and pervade the entirety of his work (Bourdieu, 1984; 1979: 11-52; 1989: 373-481; 1980b; 1980: 187-237). In this sense, contrary to the defence put forth by Collins (2004: 221), Bourdieu's perspective includes different analytical schemes and conceptual definitions to embrace both the multidimensionality of social structure and the different modalities of power resources and their conditions of social existence. In addition to the entire dynamic of formulation and organisation and defence of interests through different modalities, such as corporatism and the meritocratic ideologies based on 'talent', the social hierarchisation based on resources not explicit as such is more directly expressed through the conceptualisation of social capital (Bourdieu, 1980b; 1989: 236, 418-419, 439, 476). However, despite the nominal coincidence, this definition neither approachesnor maintains any type of relationship with those conceptualizations based on civic morality, such as in the case of Coleman (1988) and Putnam (1992).

On the other hand, as an extreme example of the appropriation of Weber's formulations from a specific perspective, differing towards credentialism as much as towards Bourdieu, is a group of authors dedicated to the study of education as a means of ascension or social mobility, among which Goldthorpe (2014) stands out. With his past participation in the elaboration of a classification scheme of occupations that is distinguished by its emphasis on a multidimensional perspective (Erikson et al., 1983), recently, he takes a more explicit position defending approaches centred on the socalled 'triage' theory and signalling and other similar approaches stemming from the propositions of economists as an alternative to the human capital theory and in opposition to credentialism and Bourdieu's approach. Besides the idea of specificity in the labour market, due to the inseparability between work and the worker, for the position against the formulations of credentialism and Bourdieu, he argues that, for these approaches, education would serve 'the interests of groups or class, instead of organisational or social interests' (Goldthorpe, 2014: 272-273). In summary, it is evident that, more than conceptual definitions, the clashes between values and conceptions of society are being considered, when the opposition between theoretical perspectives is based on conflicts between doctrines, from which also arises the confusion between socially dominant structural position and 'interests of groups or class'. Accordingly, it is important to highlight that the definition of labour relationships or domination in general only based on the specificities of the formal work contract, such as sustained by Goldthorpe (2014), is limited and insufficient to account for the effects of social position in the differentiated appreciation of formal education. This is because, in respect to labour relationships, this multidimensionality is assumed mainly by the dependence and rules contained in the formal work 'contract' and not in the set of authority relationships of the social structure.

Regarding the theoretical position generally designated as 'credentialism', it should be emphasised that recently, there have been some important additions and the degree of convergence with Bourdieu's propositions has increased. In particular, it deals with Brown's propositions (2001) in the sense of differentiated conditions of relationships with schooling according to social position and in the labour market. Focusing especially on the United States, the propositions highlight the specification of the relationships of schooling with the social conditions of its appreciation, linked to the multidimensionality of the social structure and with relative autonomy from different markets and spheres. This variety of markets and organisations is synthesised in two types, that is, the bureaucratic modality and the professional work market. In the hierarchy of the bureaucratic labour market, educational credentials offer two forms of social control. For the lower level positions, the credential serves as a 'signal' or indication of competence for the exercise of routine tasks, thus reducing the degree of uncertainty in recruitment. For the highest positions such as administrators, the emphasis is focused on the cultural character of the credentials, with strong connections with the elite of graduates in Liberal Arts and courses related to business administration and law schools (Brown, 2001: 27-28). In the professional work market, the uses of credentials have differences as regards bureaucratic recruitment and present two characteristics: self-recruitment and self-regulation (Brown, 2001: 28).

Since this paper indicates the strong association among certain occupational groups-especially the legislators, senior officials and managers, and in relation to status in employment of the employers - the propositions about the special position of leadership groups (Brown, 2001) are of special interest. However, there is another interesting aspect present in this formulation, although it is not very explicit in the current bibliography, which consists of the specific relationships with the social and bureaucratic rules in general, despite Brown's (2001) emphasis on the cultural aspects in the recruitment of leadership groups. 
It is more specifically about the relationships with the bureaucratic and social rules in a broader sense than those contained in the 'contract', highlighted by Erikson et al. (1983), covering the various positions of power. This issue is far from being exhausted in the social sciences and has been the object of study in American sociology, at least since the middle of the last century, as seen with the direct influence of Weber's formulations and particularly in the work of Mills (1962). For this paper's agenda, the findings are of interest regarding relationships with the bureaucratic rules and co-optation in accordance with the position in the social and business hierarchy. According to Mills (1962: 166-177), as with the word 'entrepreneur', the word 'bureaucrat' is also inappropriate for high-level business leaders. One's selection and ascension in the hierarchy are based on personal choices and 'there are no strict and impersonal rules'. For their part, those in the middle levels are mainly specialists, with recruitment and hierarchisation criteria of their own.

These findings go along with Weber's formulations (1984), in the sense that the formal rationality of rules, including the example of bureaucracy, does not include the ends, but only the means of action. Therefore, both the direction and its agents are not subordinated to this 'universality' of rules, as in this form of 'rational' domination, rules are obeyed rather than people (Weber, 1984: 706). Thus, the bureaucratic domination includes a non-bureaucratic element, which is contained in the administrative framework (Weber, 1984: 177). In this sense, through the 'professional secrecy' in administrative bodies, the capitalist entrepreneur is excluded or is 'immune' to bureaucratic or rational/legal domination (Weber, 1984: 179, 1100). However, This should be highlighted as not only in sociological appropriations but also in the modernist ideologies, such as school meritocracy, there is a tendency to confuse the social division of industrial or entrepreneurial work in general with its inclusion in the bureaucratic rules encompassing the governing bodies. This includes the statistical classification schemes themselves.

Unlike the position of Schultheis (1998), in the sense that an international comparison based on statistics may consist in the confrontation between administrative categories contained in the classification schemes, the sources made up of these surveys can be fertile for research. This, of course, not only eliminates their limitations but also the need for control of their bases and principles of classification, since their objectives are not the instrumentalisation of social sciences but of government policies.

Generally, a characteristic of a good part of the schemes prior to the ISCO-88 was the inclusion of classifications based on condition. In this classification, based on conditions or on occupations associated with the possession of certain resources, one of the effects is the specification of categories associated with the possession or control of economic capital, such as the 'owners' or 'employers' as categories or occupational groups. In turn, the ISCO-88 scheme of classification is placed in a meritocratic ideology, which prioritises and views, as almost exclusive, the social division of labour and the alleged 'competence' required to exercise a specific occupation as a criterion for defining and grouping.

Both the ISCO-88 and the ISCO-08 are centred on the concepts of job and skill. In the ISCO- 88 version, the 'concept of skill level was not applied in the case of major group 1, legislators, senior officials and managers and major group 0 , armed forces', attributed to its heterogeneity (International Labour Organization,2007). In the ISCO-08 version, it is applied to the 10 large groups of the scheme based on skills or the equivalent level of schooling. (International Labour Organization, 2007). To circumvent guideline problems in relation to the classification scheme and in accordance with the skill or level of schooling, in the ISCO-08 version, the criteria for the armed forces were also altered. With regard to the managers, the large group was also divided, with the allocation of specific skill levels, such as legislators and senior officials, corporate managers and general managers, that is, with the size of the work organization as an additional criterion (International Labour Organization, 1988).

\section{Sources and main indicators}

The sources of the empirical materials used in this paper consist of censuses from different countries that provided the variables and relevant information. From all the countries with data made compatible by IPUMS International ( Minnesota Population Center, 2018), seven were included for in-depth examination: US, Brazil, Canada, South Africa, Sri Lanka and Mexico. In addition to the total incomes in continuous values, the censuses of these countries provided information relating to their major study at university and other detailed information regarding occupational classifications and the status in employment (class of worker). Since the analysis of the relationships between occupational destination and the income of university graduates is the focus of this investigation, only the components of this universe composed by university graduates were extracted.

As to their income, the variable used in a more general manner was the total income, as it is more comprehensive than other aspects such as earned income. For some countries with more complete and detailed information, particularly the US and Puerto Rico, information relating to other types of income was used for comparison. 
The objective of this comparison between specific types of income was to acquire some approximation or indication about the composition of these incomes, particularly from work and investments. The ideal would be to use specific indicators such as the amount of financial assets, which was not available. However, in addition to the different sources of income, there is a problem with the current definition of 'occupation', which includes the activities of 'management'. It also refers to a more general problem, which is the complexity of the sources of income and its relationships with economic property, already highlighted by authors such as Mills (1962) and Bourdieu (1989). Mills (1962: 148-166) highlights the relationships of interdependence between the business world or the 'economic circles' and 'senior executives'. Similarly, Bourdieu (1989: 476-478) indicates that, in addition to the personification of relationships between leaders of economic power, studies on the relationships between owners and managers tend to focus exclusively on ownership titles. However, large economic establishments accumulate 'grands commis', which cannot be measured solely by economic indices.

Initially, the indicators of income were correlated with the categories of schooling, occupation and status in employment. However, in view of the very compelling evidence that, in addition to the strong hierarchisation of those trained in university courses in accordance with the occupational destination, the position relative to the status in employment is heavily interdependent - a simultaneous examination was made. That is, the occupational categories in their hierarchisation by income were correlated with those of the status in employment. The general observation, monotonously overwhelming, was that each occupational group ranks itself relative to the amount of income and maintains a second hierarchisation according to the respective category of the status in employment. If in respect to occupational groups, legislators, senior officials and managers are always at the top, in addition to occasional exceptions such as professionals, with regard to the status in employment, the employers (or equivalent) constitute the almost exclusive category at the top of the hierarchy or above the general average of the whole universe. In view of the large number of occupational categories, the more detailed examination was restricted to the more clustered level with 10 groups, although the same exam can be applied to each category at a more expanded and specific level.

In addition to this introductory item, the following item introduces the main trends found in the examination of the occupational destination in its relationships with the distribution in large occupational groups and in categories of status in employment. The investigated hypothesis is that, more than one's major, the most decisive factor in determining positive relationships between occupational destination and the amount of income is one's suitability to occupations that are equivalent to higher social positions and/or associated with the exercise of activities of command or management. These relationships are even more intense when juxtaposing the categories of occupational classifications with those of the status in employment and, particularly, with those linked to command functions, such as those of employers or equivalent.

\section{Occupation, status in employment and income}

As mentioned before, this paper discusses the relationships of the condition of university graduates with their occupational destination group and category in the status in employment. With respect to the position classifications in the status in employment, of the two versions available, the more detailed one was used seeking to reduce excessive generality. Even so, some categories are still not very discriminating due to their high degree of generality, especially in regard to 'salaried employees' or similar. In addition, the schemes used in the more detailed version are different in the composition and number of categories. Despite this, for the main categories and those more directly indicative of social position, such as 'employers' or similar, they are all available in all the censuses of the seven countries examined.

Seeking a more detailed examination of the relationship between occupational destination among groups and categories of status in employment and their differentiated effects on the person's income, these two indicators-occupational classification and status in employment-were examined together in their interdependence. This was done to simultaneously assess the relationships of belonging to each group as occupational destination in their respective income averages and for each group taken separately, the effects of these distribution averages in the categories of the position in the status in employment. In this way, there was an intersection of two hierarchisation modalities according to income, one based on the occupational group and, for each group, its division and hierarchisation is according to the categories of position in the occupation.

The results were strikingly compelling and systematic. Despite the inclusion of censuses from seven countries, variations were restricted to only a few cases, usually not to a very considerable degree. For almost all countries examined, in general, despite the strong hierarchisation in the income averages of occupational groups, when correlated with the categories of position in the status in employment, only 'employers'(in rare cases, a few other specific categories, usually public officials) are at the pole of higher incomes. 
Beginning with the US, which has better sources, in the 2010 census, when examining the 10 occupational groups by total income average, the only group that stands above the general average of the whole universe is that of legislators, senior officials and managers (average of 1.37 times the whole census universe) ${ }^{1}$. In addition to this group, only the one for professionals (1.06 times the average of the whole universe) and the one for armed forces (1.05 times) are above the overall average, but not as significant. At the extreme of the lowest total income averages, groups that stand out are the elementary occupations ( 0.41 times the average of the whole universe), clerks ( 0.54 times), among others immediately above.

As already mentioned, each of these 10 groups ranks itself internally, according to the category of the status in employment of occupational destination, and the category almost isolated of the position in the occupation that is above the total income average of the whole group is 'employers' or similar. In the case of the US, the classification scheme for status in employment regarding the category 'employer' can be considered equivalent or similar to that of selfemployed incorporated. In this case, it is the only category with its total income average significantly above that of the entire group of legislators, senior officials and managers (1.16 times the group average), in addition to the incorporated self-employed, and the wage/salary worker, private employer with an income average slightly above that of the whole universe (1.05 times). Therefore, more than the components of the group of legislators, senior officials and managers, this group has higher average incomes and are employers or incorporated self-employed.

With minor variations, these results are equivalent to other occupational groups in the US in their relationships with the status in employment and total income averages. For the group of professionals, those who are also employers or incorporated self-employed, the average of total income is twice that of the whole group. In the case of professionals, in addition to the incorporated self-employed, the unincorporated self-employed also have a total income average above that of the whole group, although to a lesser degree (1.13 times). Something similar occurs with the wage/salary workers, private employer (1.14 times) or federal government employees (1.19 times).

The group of technicians and associate professionals maintains a virtually identical internal hierarchisation for the status in employment. At the pole of the highest averages, the incorporated self-employed (1.32 times the average of the whole group) stand out. In addition to the incorporated self-employed, in this group, only the federal government employees have an average income significantly above that of the group (1.18 times), and to a lesser degree, virtually insignificant, the wage/salary worker, private employer (1.08 times).

Regarding the group of clerks, despite its low position in comparison to the total income average of other groups, it maintains virtually the same internal hierarchy for the status in employment. In this case also, at the pole of averages above that of the whole group, only the incorporated self-employed (1.49 times) and the federal government employees (1.26 times) stand out.

Something similar occurs for the group of service workers and shop and market sales. Only those who fall within the categories of incorporated self-employed (1.39 times), federal government employee (1.44 times), and local government employee (1.23 times) have a total income average above that of the group. Therefore, in this case, the local government employees are included among those who are above the group average, certainly because of the lower overall average of the group. The group of skilled agricultural and fishery workers repeats the same general pattern, with only incorporated self-employed (1.39 times), and federal government employees (1.20 times) being above the average for the whole group. Similarly, in the group of craft and related trades workers at the upper end of the total income average, the incorporated self-employed (1.17 times) and the federal government employees (1.24 times) stand out. However, in this case, the local government employees group is also above the average for the whole group (1.18 times), certainly because of the lower overall average of the whole group. In the case of the group of plant and machine operators and assemblers, due to the group's lower average, the federal government employees (1.47 times) are at the upper end and the incorporated self-employed (1.12 times) are only in a secondary position, jointly with local government employees (1.12 times). At the lower end, the same categories are there as in the other groups.

Finally, regarding the US, the group of elementary occupations is at the lower end of the hierarchy of groups (only 0.41 times the total income average of the whole census universe) and, certainly in association with this, the position of the incorporated self-employed is more prominent (1.62 times the average of the whole group). Immediately below, the federal government employees (1.56 times) stand out and, to a lesser degree, the state government employees (1.24 times).

\footnotetext{
${ }^{1}$ The average income of each category was divided by the whole universe average and subsequently, the ratio between the
} two was calculated. Therefore, the displayed number represents the ratio between the averages. 
Since the other six countries examined in this paper have results very similar to those of the US, with only slight variations of degree, but not in their ranking, their detailed presentation was not deemed necessary. Therefore, only the most significant differences or peculiarities have been highlighted.

In addition to the US, Puerto Rico also uses the same statistical classification scheme for the status in employment and occupational groups. With respect to the hierarchy of occupational groups according to total income, one of the peculiarities of Puerto Rico, also noticeable in the 2010 census, is the position of the armed forces at the top, with almost twice (1.75 times) the average of the whole universe. In addition to the armed forces, only legislators, senior officials and managers (1.59 times) and skilled agricultural and fishery workers (1.32 times) have a total income average above that of the whole universe, in addition to the group of professionals, although with little significance (1.08 times).

Considering the groups in Puerto Rico by their relationships with the status in employment and starting with legislators, senior officials and managers, at the upper end, the incorporated self-employed (1.39 times the group average) stands out and, to a lesser extent, the wage/salary workers (1.14 times). At the lower end are the unincorporated self-employed ( 0.53 times). In the group of professionals, there is a larger number of categories with an average above that of the group. Moreover, in this case, the professionals at the top of the hierarchy are the incorporated self-employed (1.98 times), immediately followed by the unincorporated self-employed (1.62 times);and situated above the average are the federal government employees, although to a lesser degree (1.21 times). The group of technicians follows the same pattern, with the incorporated self-employed at the top (1.61 times), but with a non-significant superiority of the overall average of the unincorporated self-employed (1.09 times) and greater for the federal government employees (1.61 times). For the group of clerks, the main feature is the position at the top of the unincorporated self-employed (1.93 times), followed immediately by the incorporated self-employed (1.55 times) and further still by state government employees (1.13 times). In the group of service workers and shop and market sales, only the incorporated selfemployed (1.95 times) and the federal government employees (1.19 times) have an average significantly greater than that of the whole group. As for the group of skilled agricultural and fishery workers, only the incorporated selfemployed (1.82 times) and the different categories of public servants are above the average of the whole group. For the group of craft and related trades workers, only the state government employees have an average significantly greater than that of the group (1.50 times). In the group of plant and machine operators and assemblers, only the incorporated self-employed have an average significantly above the group (1.38 times) and, to a lesser degree, the state government employees (1.07 times). Finally, in the group of elementary occupations, only the incorporated self-employed have an average significantly above the group (1.22 times) and, to a lesser degree, the wage/salary worker, private employer (1.08 times).

The results for Brazil, although it is a peripheral country, are very similar to those of the US and other countries. In the hierarchy of occupational groups by total income average, the legislators, senior officials and managers are at the top (1.59 times the average of the whole census universe), followed immediately by the skilled agricultural and fishery workers (1.33 times) and, to a lesser degree, by the group of professionals (1.06 times). The skilled agricultural and fishery workers group breaks the pattern to a very small degree, certainly due to the classification scheme. All the other groups are below the average of the whole universe.

In the case of Brazil, unlike the US and Puerto Rico, the classification scheme of the status in employment specifies the category of employers. In the case of the legislators, senior officials and managers group, this category of employers is the only one with average income above that of the group (1.42 times). Moreover, in the case of the professionals group, the highest total income average is that of employers (2.12 times), with more than twice the group's average. However, in this case, other categories are also above the average, such as the unpaid family workers (1.62 times) and those working on own account (1.28 times). Further, in the group of technicians and associate professionals, employers are at the top (1.88 times), but in this case, the main difference is the position above the average, although to a lesser degree, of the wage/salary worker, government (1.38 times); and situated above average, although to a lesser degree, are those working on own account (1.14 times). In the case of the clerks group, the position of employers at the upper end is even more striking, surpassing the average of the group by a factor of four (4 times). To a lesser degree, those working on own account (1.64 times), the wage/salary worker, government (1.29 times) and the unpaid family worker (1.40 times) are above the overall average of the group. In the group of service workers and shop and market sales, only the employers (1.91 times) and the wage/salary worker, government (1.46 times) are significantly above the average and, to a lesser degree, those working on own account (1.07 times). Essentially, this result is similar to the result obtained for the skilled agricultural and fishery workers, with employers with twice the average of the group ( 2 times), followed by wage/salary workers, government (1.28 times), with all the other categories below the overall average. In the case of crafts and related trades workers, the wage/salary worker, government (1.76 times) are the ones at the top, followed by employers (1.43 times). 
This is similar to the results obtained for the plant and machine operators and assemblers with employers at the top (1.86 times), but with unpaid family workers in the second position (1.98 times), and wage/salary worker, government (1.27 times) only in the third position. Finally, there is the group of elementary occupations, where employers are also at the top, with more than three times (3.13 times) the general total income average. In this case, also situated above the overall average, to a lesser degree, are the unpaid family worker (1.51 times), working on own account (1.21 times) and wage/salary worker, government (1.14 times). At the lower end is the category of employees without legal contract (0.64 times).

In the case of Canada, the differences between occupational groups in relation to the total income average are much smaller than for the other countries examined. Only the group of legislators, senior officials and managers (1.45 times the average of the whole census universe) and, to a lesser extent, the professionals (1.08 times) are above the overall average of the census universe. Therefore, all the other groups have lower average, with both elementary occupations (0.51 times) and service workers and shop and market sales (0.52 times) at the lower end.

Regarding the categories of the classification in the status in employment in Canada (2001 census), there are only three categories: employer, working on own account, and wage/salary worker. In any case, in terms of the group of legislators, senior officials and managers, only those who are wage/salary workers are above the average of the whole group, but to a very small degree(1.05 times). At the lower end are those working on own account (0.60 times). In the group of professionals, the situation is very different, with employers at the top (1.75 times) and wage/salary workers at the lower end. The group of technicians and associate professionals have a similar situation, with employers as a single category above the average of the whole group (1.64 times). The same occurs with the clerks, with only the employers being above the average (1.36 times). This also applies to the group of service workers and shop and market sales, with only the employers above the average (1.33 times), followed by the group of skilled agricultural and fishery workers (1.30 times). In the group of crafts and related trades workers something distinct occurs, with only the wage/salary worker above the average for the whole of the group and only slightly so (1.04 times). The same occurs with the group of plant and machine operators and assemblers, to a lesser degree (1.01 times for the wage/salary worker) and, finally, in the case of the elementary occupations group, this small advantage is for those working on own account.

For South Africa (1996 census), the results follow the same pattern. With respect to the hierarchy of groups by total income average, the legislators, senior officials and managers are at the top (1.52 times the average of the whole universe) and, in addition to those, only the plant and machine operators and assemblers are significantly above the overall average (1.21 times). In this case, at the lower end, the group of clerks stands out, with little more than half $(0.50)$ of the overall average.

Regarding relationships with the status in employment, in the case of South Africa, there are only four categories: employer, working on own account, wage/salary worker and unpaid family worker. In the group of legislators, senior officials and managers, no category stands out, with only a slight advantage for the wage/salary worker (group average of 1.03). The situation of the group of professionals is different, with emphasis on the employers at the top (1.73 times the group average), followed, to a lesser degree, by working on own account (1.14 times). For the group of technicians and associate professionals, only the employers have an average greater than that of the group (1.54 times). The situation of the clerks is similar to that of the professionals, with employers (1.41 times) and, to a lesser degree, those working on own account (1.12 times greater than the overall average). Moreover, for the group of service worker and shop and market sales, only the employers are above the average of the group (1.27 times). Even for the skilled agricultural and fishery workers, only the employers are above the average of the group (1.08 times), in the same way as the crafts and related trades workers, to a lesser degree (1.24 times). In the group of plant and machine operators and assemblers, something distinct occurs, with only the wage/salary worker being slightly above the average of the group (1.08 times). Finally, even for the elementary occupations, only the category of employers is above the average of the group (1.29 times).

For the Dominican Republic, the results are very similar and follow the same pattern as the other countries. In the hierarchy of occupational groups by total income average, the legislators, senior officials and managers, with almost twice the average of the whole universe (1.92 times), are at the top, along with the armed forces (1.37 times). To a lesser degree, the group of professionals is also situated above the average (1.06 times). At the lower end, the group of elementary occupations ( 0.44 times) stands out.

In the Dominican Republic, the relationships of the group of legislators, senior officials and managers with the status in employment by the total income average, only employers are above the average of the whole group (1.11 times). Something similar occurs in the group of professionals, with employers in a position even higher (1.55 times). For the group of technicians and associate professionals, in addition to the employers (1.72 times), the self-employed also have an average greater than that of the group (1.27 times). 
In the case of the clerks, only the employers have an average above that of the group, surpassing it by more than double (2.14 times). For the service workers and shop and market sales, the employers (1.41 times) and, to a lesser degree, the self-employed (1.01 times) are above the overall average. For the skilled agricultural and fishery workers, there is a small variation, with employers at the top (1.42 times) and wage/salary workers also slightly above the overall average. In the case of crafts and related trades workers, only employers are above the average of the group, almost twice (1.86 times). For the group of plant and machine operators and assemblers, there is a small variation, with employers at the upper end (1.78 times) and with the members of cooperative slightly above the average of the group (1.11 times). Finally, the elementary occupations, where employers have almost twice the average (1.87 times) of the whole group and, to a lesser degree, the members of cooperative stand above the general average (1.43 times).

Finally, Mexico (2010 census) offers more complete information for earned income, to the detriment of total income. In any case, the results are very similar to those obtained in other countries. In the hierarchy of groups by average of earned income, the armed forces (1.59 times the average of the whole census universe) are at the top, followed by the group of legislators, senior officials and managers (1.51 times) and, to a lesser degree, of professionals (1.07 times).

Regarding the hierarchisation of relationships with the status in employment, despite the particularity of the inclusion of specific categories such as day labourers, the results are similar to those of other countries examined, with minor variations, but always with employers noticeably at the top of the income average. Therefore, a detailed presentation was not deemed necessary.

\section{Discussion and conclusions}

As mentioned in the introduction, the central theme of the relationships between the occupational destination of university graduates and their income covers a series of broader analytical problems. As indicated, the occupational destinations of these university graduates are relatively dispersed, significantly encompassing a series of occupational groups.

To efficiently investigate the hierarchisation regarding the amount of income according to the occupational destination, the differences of income in relation to the classifications in occupational groups were examined and, simultaneously, the internal hierarchisation associated with the status in employment categories (i.e. class of worker).

The more general result of this examination is the strong hierarchisation of university graduates, considered as much in occupational groups as in status in employment. These results are also very striking regarding the interdependence of occupational destinations in occupational classifications and in relation to the status in employment. Briefly, in all seven countries examined, with respect to income regarding the occupational classifications in its latest, most conciseversion, the legislators, official and senior managers group are at the top of the hierarchy, followed by the professionals group and, in some cases, by the armed forces. All other groups tend to be situated towards the lower income average, with the group for elementary occupations at the lower end. At the same time, with regard to the status in employment, the employers or equivalent categories always stand out at the top of the hierarchy, usually being the only category positioned significantly above the average in relation to the rest of the group. The same occurs when examining the relationships of each group with the categories of status in employment, which results in a hierarchisation, wherein those who are also employers stand out at the top, generally being the only category above the average. In summary, in the hierarchisation of university graduates, the central element is the relationships with the condition of 'administrator' or 'employer'.

Thus, although the results obtained are significant and systematic, they raise more questions than answers, which can be considered a positive occurrence. On the one hand, such problems that remain open arise from limitations on the sources of empirical material and the underlying classification schemes, but on the other hand, they are linked to the theoretical and conceptual limitations of the social sciences themselves.

On its most general level, the main problem is associated with the perspectives in the social sciences of analysing the social division of labour and its relations with social hierarchisation. As mentioned previously, from the perspective of Weber (1984), the rational/legal domination or its exemplary case - the bureaucracy — does not include the purpose of the actions and the positions of command in its characteristic instrumental rationality. Thus, despite the subsequent uses in view of the reasoning of theories of modernisation and modernist ideologies, rationalisation and the social division of labour do not reduce the problems of defining the position and functions of the 'administrators'. On the other hand, in addition to the problems linked to the multidimensionality of social structure, there is the problem of the logic of action and rationality of what is included in the position and function of 'administrator'. At this point, in addition to the limitations of the sources of empirical material and their classification schemes, the uses of instrumental rationality as a foundation of meaning or purposes of actions come into question. 
Beyond the limitations of this study, it is possible to glimpse some tendencies that underlie the prominence of 'administrators' on the income hierarchies. In addition to the limits of the possibilities of discerning relationships between earnings arising from professional activities and the economic return on investments, other theoretical issues are imposed. One of these issues is the relationships between the social division of labour and the anonymity orimpersonality implied in the social objectivation of the rational/legal domination as the principle of social structuring and, conversely, as a principle of legitimation. If, on the one hand, the expansion of capitalism and technical expertise is based on the impersonality of certain spheres of the work structures and processes, as mentioned before, the purposes of the actions for the administrative framework or the management of these processes is excluded from the principles that govern the rational/legal domination. On the other hand, with the expansion of capitalism, not only do its structural activities and relationships assume other contours, but also the new the odicies of the 'spirit of capitalism' tend to overestimate the activities of 'management' or manipulation of relationships and, consequently, the personification of professional relationships as something positive. Thus, although the division of labour based on technical expertise remains central to social structuring, it increases the weight of the personification of relationships, particularly those associated with management.

The strength of this type of theodicy, which over-appreciates the personified character of the relationships of management or command, is not restricted to the spheres and agents directly involved in the social processes being considered. It also covers a good part of the social sciences, which could not be detailed here. As mentioned previously, at the root of these formulations are the propositions by Weber (1984), particularly with respect to the socially objectified and encoded dimensions of social structure, faced with the more implicit or tacit principles of hierarchisation of character. For this discussion, the most important thing to highlight is that these relationships between the explicit and encoded principles of hierarchisation and the implicit and tacit are present differently at different levels of the social structure, which includes both spheres based on rational/legal domination and personified relationships. In this case, the spheres associated with command or management particularly stand out.

In specific regard to the most immediate problem of this paper, that which deals with the conditions of appreciation of formal education, this opposition between the more objectified and encoded dimensions and those centred on implicit or tacit principles is the basis of the theoretical positions in opposition. On the one hand, there are the perspectives associated with the human capital theory, based on the premise of the value of education because of something intrinsic and objectified, resulting from the productivity of the labour it can elicit. On the other hand, despite the differences among themselves, all theoretical positions in opposition are based on the premise of the appreciation of formal education because of social conditions associated with personified relationships. These are the effects of using academic degrees as 'credentials' in the perspective of credentialism, of using relationships based on personified relationships grounded in ideologies of 'talent' or even in the social capital as formulated by Bourdieu and so forth. The main problem stems from the lack of any general theory that could address the assembly of these partial aspects of dimensions and personified relationships. It is likely that this absence of a general theory, unlike the dimensions more socially objectified, arises from the very social force of modernist theodicies, such as the sociological theories of modernisation themselves. Nevertheless, in addition to the effects of using academic degrees as a credential, of the ideologies of the 'talent', and the effects of personification on the relationships of command or management, of social capital, among other possible analytical precepts, the findings of this paper point towards the importance of the effects of the conditions of the manipulation of social rules. However, the issue is not just the contractual rules in the labour market, but the effects of the social position itself, particularly in association with situations of command or management. Finally, it is worth noting that these problems are directly present in the very classification schemes that are at the basis of the statistical sources available.

Conflict of interest: The author declare that there is no conflict of interest

Funding: This research received no grant from any agency in the public, commercial, or not-for-profit sectors.

\section{References}

Bourdieu P (1980) Le Sens Pratique. Paris: Les Éditions de Minuit.

Bourdieu P (1989) La Noblesse d'État; Grandes Écoles et Esprit de Corps. Paris: Les Éditions de Minuit.

Bourdieu P (1980b) Le capital social.Actes de la Recherche en Sciences Sociales 31(1): 2-3.

Bourdieu P (1984) Homo Academicus. Paris: Les Éditions de Minuit.

Bourdieu P (2009) O Senso Prático[The Practical Sense]. Paris: Les Éditions de Minuit.

Brown DK (2001) The social sources of educational credentialism: status cultures, labor markets, and organizations.Sociology of Education 74:19-34. 
Coleman JS (1988) Social capital in the creation of human capital. American Journal of Sociology94:S95-S120.

Collins R (1979) The Credential Society: An Historical Sociology of Education and Stratification. Cambridge: Academic Press.

Collins R (2004) Lenski's power theory of economic inequality: acentral neglected question in stratification research.Sociological Theory 22(2):210-228.

Erikson R, Goldthorpe JH and Portocarero L (1983) Intergenerational social mobility and the convergence thesis. British Journal of Sociology 34(3): 303-343.

Goldthorpe JH (2014) The role of education in intergenerational social mobility: Problems from empirical research in sociology and some theoretical pointers from economics.Rationality and Society, 26(3):265-289

International Labour Organization (2007) International Standard Classification of Occupations: ISCO-08 Structure, index correspondence with ISCO-88. Available at: http://www.ilo.org/public/english/bureau/stat/isco/isco08/index.htm(accessed in 20/02/2018)

International Labour Organization (1988) International Standard Classification of Occupations: Major Group 1: Legislators, Senior Officials and Managers. Available at: http://www.ilo.org/public/english/bureau/stat/isco/isco88/1.htm (accessed in 10/01/2017)

Mills CW (1956) The Power Elite.New York:Oxford University Press.

Minnesota Population Center (2018) Integrated Public Use Microdata Series, International: Version 7.0 [dataset]. Minneapolis: IPUMS.

Putnam RD (1992) Making Democracy Work; Civic Traditions in Modern Italy. Princeton: Princeton University Press.

Schultheis F (1998)L'Identite dans les comparaisons internationales: une imposition de categories administratives.Regards Sociologiques 16:51-60

Weber M (1984) Economia y Sociedade: Esbozo de Sociología Comprensiva. [Economy and Society: Outline of Comprehensive Sociology]. México: Fondo de Cultura Económica. 